\title{
Predictors of Reoperation Requirement on latrogenic Chylothorax after Thoracic Surgery
}

\author{
Hıdır Esme (D), Ferdane Melike Duran (D) \\ Department of Thoracic Surgery, Health Sciences University, Konya Training and Research Hospital, Konya, Turkey
}

ORCID iDs of the authors: HıdırE. 0000-0002-0I84-5377; F.M.D. 0000-0002-2886-7285

Cite this article as: Esme H, Duran FM. Predictors of Reoperation Requirement on latrogenic Chylothorax after Thoracic Surgery. Cyprus J Med Sci. 2021; 6(3): 230-233.

\section{BACKGROUND/AIMS}

We reviewed our experience with iatrogenic chylothorax after general thoracic surgical procedures to identify factors that predict the need for reoperation and to evaluate the success of management.

\begin{abstract}
MATERIAL and METHODS
Between January 2010 and July 2018, 3,640 general thoracic surgical procedures were performed at our institution, and iatrogenic chylothorax developed in 19 patients. The medical records of these 19 patients were reviewed for age, sex, preoperative history, operative and pathologic findings, amount of daily chest tube (CT) output, and method of management of the chylothorax. We compared the differences in triglyceride value, triglyceride/cholesterol rate, the CT output for the daily before reoperation, and the first 24 hours and 5 post-operative days between the conservatively cured group and reoperation group.
\end{abstract}

\section{RESULTS}

Pulmonary operations were performed in 14 patients, mediastinal operations were performed in four, and esophageal operation was performed in one. All patients were initially treated by complete cessation of oral intake and total parenteral nutrition, talc pleurodesis, and somatostatin. This treatment was successful for 12 patients. The remaining seven patients (36.8\%) required reoperation to control the chylothorax. There were significant differences between the conservatively cured group and reoperation group for CT output for the first 24 hours and 5 days and triglyceride/cholesterol rate.

\section{CONCLUSION}

The CT output greater than $950 \mathrm{~mL}_{\text {day }}{ }^{-1}$ for the first day or $1,000 \mathrm{~mL}_{\text {day }}{ }^{-1}$ for the first 5 days and the development of a chylothorax after an esophageal operation are significant factors that predicted the need for reoperation.

Keywords: latrogenic chylothorax, management, reoperation

\section{INTRODUCTION}

Chylothorax can result from benign or malignant occlusion of the thoracic duct resulting in collateral formation or disruption of the main thoracic duct with subsequent leakage of lymph into the pleural space.' latrogenic chylothorax is a rare but well-known complication in thoracic surgery. latrogenic chylothorax ranges from 0.5 to $10.5 \%$ after esophagectomy ${ }^{2-4}$ and from 1.4 to $2.3 \%$ after lung resection., At an early stage, chylothorax can lead to severe cardiorespiratory and volemic complications. In the case of chronicization, malnutrition and immunologic complications can occur, responsible for a mortality rate of up to $50 \%$. Optimal management of chylothorax can decrease mortality. ${ }^{7}$ Optimal management remains a subject of debate. Some authors advocate conservative treatment, while others propose early surgery. We reviewed our experience with iatrogenic chylothorax after general thoracic surgical procedures to identify factors that predict the need for reoperation and to evaluate the success of management.

\section{MATERIAL and METHODS}

Between January 2010 and July 2018, 3,640 general thoracic surgical procedures were performed at our institution, and iatrogenic chylothorax developed in 19 patients (0.52\%); these patients constituted the subjects in this study. Ethics committee approval was received for this study from the local ethics committee of the University of Health Sciences, Konya 
City Hospital (224/ 04.01.2019). A written informed consent was obtained from patients who participated in this study. The diagnosis was established by a triglyceride content of $110 \mathrm{mg}$ $\mathrm{dL}^{-1}$ or greater in the pleural fluid in all patients. The medical records of these 19 patients were reviewed for age, sex, preoperative history, operative and pathologic findings, amount of daily chest tube (CT) output, and method of management of the chylothorax. Follow-up data were obtained from the patients' most recent clinic visits and telephone interviews.

There were 12 male and seven female patients, with a median age of 56 years (range 4-82). Significant medical conditions were present before initial thoracotomy in nine patients $(47.3 \%)$ and included hypertension in five, chronic obstructive pulmonary disease in three, diabetes mellitus in two, and lymphoma, breast cancer, and atrial fibrillation in one each. The initial operations were performed for lung cancer in II patients, mediastinal mass in four, empyema in two, and esophageal cancer, pulmonary metastases, and palmar hyperhydrosis in one each.

\section{Observation}

We initially treated conservatively with complete oral intake cessation and total parenteral nutrition (TPN). If CT output did not decrease significantly in about 3 days, we performed talc pleurodesis (Steriltalc $4 \mathrm{~g}$; Biotema, İstanbul, Turkey) into the thoracic cavity through a CT. Patients received somatostatin (5 $\mu \mathrm{g} \mathrm{kg}^{-1} \mathrm{~h}^{-1}$ ) (Somatosan 3 mg; CuraMED Pharma GmbH, Wasserberg, Germany) for 7 days. Successful management was defined as resolution of cloudy CT output, volume of less than $150 \mathrm{~mL}$ day $^{-1}$, and sustained removal of the CT. If chylothorax was not cured in about 10 days, the conservative strategy was considered unsuccessful and surgical intervention was indicated.

\section{Surgical Intervention}

Patients were given olive oil until 6 hours before the operation to facilitate visualization of the leak in the operating room. The origin of the white chylous fluid was easily identified intraoperatively in three patients. Patients were undergoing thoracic duct ligation through reoperative thoracotomy or thoracoscopy. The area of the thoracic duct was explored to identify sites of leak. When leakage was detected from the ductus thoracicus, sture ligation was applied to the leakage site and lower part. Supradiaphragmatic sutures were performed when the area of the leak could not be identified. Fibrin glue was applied to the posterior mediastinum in all patients. A partial parietal pleurectomy or mechanical pleurodesis was performed in all patients.

We compared the differences in triglyceride value, triglyceride/cholesterol rate, the CT output for the daily before reoperation, and the first 24 hours and 5 post-operative days between the conservatively cured group and reoperation group using an independent $t$ test. All the statistical comparisons were made using the Statistical Package for Social Science version 16 (SPSS Inc.; Chicago, IL, USA).

\section{RESULTS}

Pulmonary operations were performed in 14 patients, mediastinal operations were performed in four, and esophageal operations were performed in one (Table I). All chylothoraces developed on the ipsilateral side. All patients had thoracos-

\begin{tabular}{lc} 
TABLE I. Cause of latrogenic Chylothorax & \\
Operation & No. \\
Pulmonary resection & \\
Bilobectomy & 2 \\
Lobectomy & 6 \\
Segmentectomy & 2 \\
Wedge resection & 1 \\
Mediastinal mass resection & 4 \\
Empyema & 2 \\
Esophagectomy & 1 \\
Sympathectomy & 1 \\
\hline
\end{tabular}

tomy tubes after their initial operation. Chylothorax was diagnosed a median of 3 days after operation (range 2-5 days). The chylothorax was on the right side in 13 patients and on the left side in six. The mean triglyceride content of the drainage was $530 \mathrm{mg} \mathrm{dL}^{-1}$ (range $12 \mathrm{I}-1,465 \mathrm{mg} \mathrm{dL}^{-1}$ ), and the mean cholesterol content of the fluid was $56 \mathrm{mg} \mathrm{dL}^{-1}$ (range $23-87 \mathrm{mg} \mathrm{dL}^{-1}$ ). All patients were initially treated by complete cessation of oral intake and TPN, talc pleurodesis, and somatostatin. This treatment was successful for 12 patients. These patients resumed a normal diet with a median of 10 days after the diagnosis of chylothorax was made (range 7-12 days). The remaining seven patients $(36.8 \%$ ) required reoperation to control the chylothorax.

Reoperation was undertaken with a median of 14 days after operation (range 12-18 days). Chylothorax developed on the right side in five patients and on the left side in two patients. The reoperation was performed on the chylothorax side in five patients and on the contralateral side in two. The approach for the reoperation was performed through the initial thoracotomy in five patients and by video-assisted thoracic surgery in two. We used the contralateral side in two patients reoperated with Video-assisted thoracic surgery (VATS). Because the adhesions are less, the ductus thoracicus is easier to find. The injury to the thoracic duct was identified at reoperation in three of the seven patients (42.8\%). The site of ligation was the supradiaphragm in four patients and immediately below the fistula

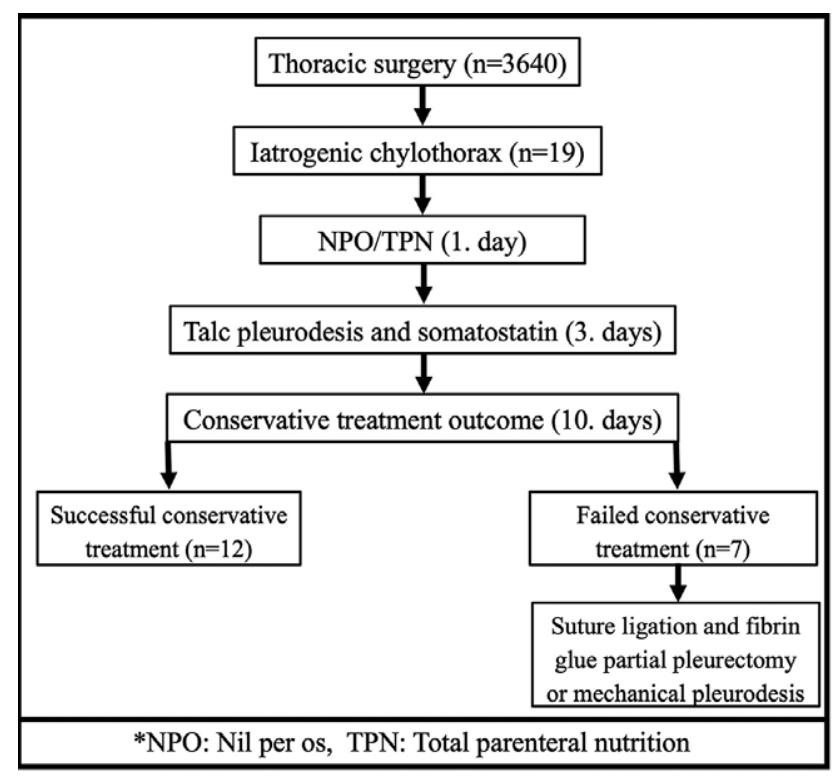

Figure I. Outcomes of treatment for iatrogenic chylothorax 


\begin{tabular}{|c|c|c|c|}
\hline Variable & Conservatively cured group $(n=12)$ & Reoperation group $(n=7)$ & $P$ value \\
\hline Triglyceride, $\mathrm{g} \mathrm{dL}^{-1}$ & $410.7 \pm 89.9$ & $735.7 \pm 151.9$ & .065 \\
\hline CT output, $\mathrm{mL} /$ first 24 hours & $521.6 \pm 51$ & $950 \pm 127.2$ & .014 \\
\hline $\mathrm{CT}$ output, $\mathrm{mL} /$ first 5 days & $461.5 \pm 27.8$ & $1004 \pm 141.7$ & .008 \\
\hline $\mathrm{CT}$ output, $\mathrm{mL}$ days $\mathrm{s}^{-1}$ (Before reoperation) & $545.5 \pm 69.8$ & $772.4 \pm 102.1$ & .076 \\
\hline
\end{tabular}

in three. Fibrin glue was applied to the posterior mediastinum in all patients. A partial parietal pleurectomy was performed in five patients, and the mechanical pleurodesis was performed in two patients. Reoperation was successful in all patients (Figure I).

There was no death among the 19 patients. Complications occurred in six patients (31.5\%): atrial fibrillation in three, prolonged air leak in two, and wound infection in one. There were significant differences between the conservatively cured group and reoperation group for CT output for the first 24 hours and 5 days and triglyceride/cholesterol rate. However, no significant differences in daily CT output and triglyceride values were observed among two groups (Table 2).

\section{DISCUSSION}

latrogenic chylothorax is an uncommon but well-known complication in thoracic surgery. In our review, we found only 19 patients with chylothorax out of 3,640 who underwent a general thoracic surgical procedure at our institution. Although chylothorax has been reported after almost every type of thoracic operation, certain patients may be predisposed toward post-operative chylothorax. Esophageal surgery is probably the most common iatrogenic cause of chylothorax with incidence reported from 0.2 to $10.5 \%$ of operations. ${ }^{4}$ Most injuries to the thoracic duct occur near the aortic and azygos arches, where the relations between the esophagus and the thoracic duct are closest. ${ }^{8}$ Pulmonary resection for lung cancer with systematic mediastinal lymph node dissection may lead to a higher incidence of post-operative chylothorax than is seen with other general thoracic surgical procedures, except for esophageal resection with mediastinal lymphadenectomy. ${ }^{3}$ Shimizu et al. ${ }^{9}$ reported that 27 patients (2.4\%) had iatrogenic chylothorax after pulmonary resection with systematic mediastinal lymph node dissection for lung cancer in their division. Among our patients, the overall incidence of iatrogenic chylothorax was $0.52 \%$; after esophagectomy, it was 10\%, and after pulmonary resection, it was $0.31 \%$. Our incidence was consistent with the literature.

Octreotide along with TPN and bowel rest is effective in reducing volume of drainage in cases of chylothorax caused by injury to thoracic duct or its branches. There is an increasing amount of evidence in the literature concerning the usefulness of octreotide, a somatostatin analog, for the conservative treatment of chylothorax. ${ }^{10,11}$ A retrospective study by Fujita and Daiko $^{12}$ of 521 esophagectomy patients, including 15 who underwent conservative therapy with octreotide vs. five without octreotide, showed significantly improved resolution ( $86 \%$ vs. $20 \%$ ). Bryant et al. ${ }^{5}$ conducted a retrospective study with the largest number of patients to date $(n=4 I)$ with chylothorax following pulmonary resections and lymphadenectomy. Success rate of the treatment with octreotide was $90 \%$. Ismail et al. ${ }^{13}$ reported in meta-analysis that the general consensus is for conservative management with octreotide to be instituted for I week before consideration of surgery. In our study, we started the somatostatin treatment on the third day of chylothorax and continued for 7 days. Success rate of our treatment with somatostatin was $63.1 \%$.

The criteria for surgical intervention described by Selle et al. ${ }^{14}$ are most frequently used in clinical practice. Selle et al. ${ }^{14}$ recommend reoperation to ligate the thoracic duct when chylous leakage persists for at least 5 days at the rate of $1,500 \mathrm{~mL}^{\text {day }}{ }^{-1}$ or more in adults and when the drainage of chyle does not decrease within 2 weeks or the patient's nutrition or metabolic status becomes measurably more impaired during the same period. Merrigan et al. ${ }^{15}$ suggest that operative intervention should be undertaken if CT output in 24 hours is I L or more for 5 consecutive days. Lagarde et al. ${ }^{16}$ proposed if drainage is $2 \mathrm{~L}$ or more after the first 2 days of optimal conservative therapy, reoperation is indicated. We found that $\mathrm{CT}$ output greater than $950 \mathrm{~mL}$ day $^{-1}$ for the first day or $1,000 \mathrm{~mL}$ day $^{-1}$ for the first 5 days and the development of a chylothorax after an esophageal operation were significant factors that predicted the need for reoperation.

For thoracic duct wounds after the chylothorax, two surgical strategies predominate: direct wound ligature or en masse supradiaphragmatic ligature. Laceration of the thoracic duct can be difficult to identify. Due to the problems encountered with localizing wounds of the thoracic duct, techniques have been developed to ligature the duct upstream, at its entry into the thorax. The method of choice is en masse ligature above the diaphragmatic hiatus among the aorta, the vertebral bodies, and the pericardium. ${ }^{17}$ This allows ligature not only of the duct, which may be injured in the process, but also of the neighboring lymphatic tissues. ${ }^{8}$ In our study, the injury to the thoracic duct was identified at reoperation in three of the seven patients $(42.8 \%)$. The site of ligation was the supradiaphragm in four patients and immediately below the fistula in three. When the reoperation is performed, pleurodesis or pleurectomy should also be performed at the same time as thoracic duct ligation. Fibrin glue application and partial parietal pleurectomy or mechanical pleurodesis were performed in all patients. The mechanical pleurodesis was performed on the contralateral side of the chylothorax by video-assisted thoracic surgery in two patients. Reoperation was successful in all patients.

In conclusion, when patients present with an iatrogenic chylothorax, we recommend an aggressive conservative management (CT drenage, nil per os/TPN, talc pleurodesis, and somatostatin). We found that CT output greater than $950 \mathrm{~mL}$ day $^{-1}$ for the first day or $1,000 \mathrm{~mL}$ day $^{-1}$ for the first 5 days and 
the development of a chylothorax after an esophageal operation were significant factors that predicted the need for reoperation.

Ethics Committee Approval: Ethical committee approval was received from the The University of Health Sciences, Konya City Hospital (224/ 04.01.2019)

Informed Consent: Written informed consent was obtained from all participants who participated in this study.

Peer-review: Externally peer-reviewed.

Author Contributions: Concept - H.E.; Design - H.E.; Supervision - H.E.; Resources - H.E., F.M.D.; Materials - H.E., F.M.D.; Data Collection and/or Processing - H.E., F.M.D.; Analysis and/or Interpretation - H.E., F.M.D.; Literature Search - H.E., F.M.D.; Writing Manuscript - H.E., F.M.D.; Critical Review - H.E.

Conflict of Interest: The authors have no conflicts of interest to declare.

Financial Disclosure: The authors declared that this study has received no financial support.

\section{REFERENCES}

I. Reisenaver JS, Puig CA, Reisenauer CJ, et al. Treatment of postsurgical chylothorax. Ann Thorac Surg. 2018;105(I):254-262. [CrossRef]

2. Sarkaria IS, Finley DJ, Bains MS, et al. Chylothorax and recurrent laryngeal nerve injury associated with robotic video-assisted mediastinal lymph node dissection. Innovations (Phila). 2015;I0(3):170-173. [CrossRef]

3. Cerfolio R, Allen M, Deschamps C, Trastek V. Postoperative chylothorax. J Thorac Cardiovasc Surg. 1996; II2(5):I36I-1365. [CrossRef]

4. Wemyss-Holden SA, Launois B, Maddern GJ. Management of thoracic duct injuries after oesophagectomy. $\mathrm{Br} J$ Surg. 2002;88(II):1442-1448. [CrossRef]

5. Bryant AS, Minnich DJ, Wei B, Cerfolio RJ. The incidence and management of postoperative chylothorax after pulmonary resection and thoracic mediastinal lymph node dissection. Ann Thorac Surg. 2014;98(I):232-235. [CrossRef]

6. Takuwa T, Yoshida J, Ono S, et al. Low-fat diet management strategy for chylothorax after pulmonary resection and lymph node dissection for primary lung cancer. J Thorac Cardiovasc Surg. 2013;|46(3):57I-574. [CrossRef]

7. Chalret Du Rieu M, Baulieux J, Rode A, Mabrut JY. J visc management of postoperative chylothorax. Surg. 20II;148(5):e346-e352. [CrossRef]

8. Sauvanet A. Surgery technique: Preventive ligation of the thoracic duct during esophagectomy for cancer. Ann Chir. 2002;127(3):22823l. [CrossRef]

9. Shimizu K, Yoshida J, Nishimura M, Takamochi K, Nakahara R, Nagai K. Treatment strategy for chylothorax after pulmonary resection and lymph node dissection for lung cancer. J Thorac Cardiovasc Surg. 2002;124(3):499-502. [CrossRef]

10. Kalomenidis I. Octreotide and chylothorax. Curr Opin Pulm Med. 2006;12(4):264-267. [CrossRef]

II. Markham KM, Glover JL, Welsh RJ, Lucas RJ, Bendick PJ. Octreotide in the treatment of thoracic duct injuries. Am Surg. 2000;66(12):1165- II67.

12. Fujita T, Daiko H. Efficacy and predictor of octreotide treatment for postoperative chylothorax after thoracic esophagectomy. World $J$ Surg. 2014;38(8):2039-2045. [CrossRef]

13. Ismail NA, Gordon J, Dunning J. The use of octreotide in the treatment of chylothorax following cardiothoracic surgery. Interact Cardiovasc Thorac Surg. 2015;20(6):848-854. [CrossRef]

14. Selle JG, Snyder WH 3rd, Schreiber JT. Chylothorax: Indications for surgery. Ann Surg. 1973;177(2):245-249. [CrossRef]

15. Merrigan BA, Winter DC, O'Sullivan GC. Chylothorax. Br J Surg. 1997;84:15-20. [CrossRef]

16. Lagarde S, Omloo J, de Jong K. Incidence and management of chyle leakage after esophagectomy. Ann Thorac Surg. 2005;80(2):449-454. [CrossRef]

17. Lampson RS. Traumatic chylothorax: A review of the literature and report of a case treated by mediastinal ligation of the thoracic duct. J Thorac Surg. 1948;17(6):778-791. [CrossRef] 